\title{
Extended Enterprise Information Sharing in a Supply Chain Environment based on Symbiosis Theory
}

\author{
Renjing Liu and Honghong He \\ School of management, Xi' an Jiaotong University, Shaanxi, \\ 710049,renjingl@163.com
}

\begin{abstract}
In modern times, the competitions between enterprises are actually the ones between supply chains. Adequate Information sharing is one of the key factors which will highly improve the efficiency of supply chain. The cooperation models of supply chain are modeled and analyzed, and a two-dimensional enterprise symbiosis model is set up to analyze the symbiosis behaviors between enterprises and the symbiosis energy functions of the model to realize that how the enterprises get their competition advantage by supply chain. According to the analysis, the importance of suitable information sharing to supply chain is obvious. Moreover, a two-dimensional enterprise information sharing model is built to express how the information sharing affects the efficiency of supply chain. To different symbiosis models, the enterprises should share different rank information to meet the demand of symbiosis. The article gives a guideline to enterprises in supply chain that how to make information sharing strategy to get a satisfactory works efficiency at a low information sharing risk rank.
\end{abstract}

\section{Introduction}

With the coming of the information economical times, the development of Information technology and information correspondence network introduces the enterprises into one new boundless digitized commercial times. In the sever competition times, if enterprises want to obtain long-term competition advantage, they must carry on the cooperation with the outstanding enterprises, and try to establish win-win cooperation relationships. The information sharing is the foundation of the cooperation between enterprises, and also is one main origin of the

Please use the following format when citing this chapter: 
supply chain advantages. Evens thinks [15] that "the supply chain management conforms the supplier, the manufacturer, retails the business, the retail merchant, until the final user company into one overall model by the forward feed information flow". Cachon and Fisher's statistical analyses prove that information sharing compares traditional order information exchange will make the average cost of supply chain save $2.2 \%$, even reach $12.1 \%$. Chen's research also indicates that effective information sharing may alleviate "bullwhip effect" Even, enterprises in supply chain establish strategy alliance to get more competition advantages through more deeply information sharing.

Although information sharing brings so many benefits, unchecked information sharing is unaccepted. Excessive information sharing also causes information sharing risk cost. Many scholars have studied this question; the main opinions are as followed:

1. The traditional supply and demand relations cause the transformation resistance.

2. Information sharing adds the enterprise's cost.

3. The corporation's business secret might leak through the information sharing.

4. Information sharing possibly reduces the enterprise bargains ability.

5. Information sharing is difficult to monitor.

6. The supply chain dynamic alliance possibly faces disintegration.

In recent years, there are also some in-depth researches (about) the problem of the actual functions of information sharing in supply chain.

Gavirneni had taken two levels of supplies chain with limited stock capacity as the research object. He obtained that the supply chain will achieve the overall benefit maximization only under the complete information sharing condition

Lee and Vhang make a summary research report on information sharing. They give us a relatively entire and qualitative definition for the types information sharing and the application of information sharing and proposed a three-rank model of information sharing.

In brief, current research on information sharing is focus on three aspects: first, the resistance of realization, the importance and necessary of information sharing in supply chain. Second, the research of information sharing model based on in request - proxy theory; third, researching on how to carry out information sharing in supply chain, Such as the structure design of EIS.

With the view of enterprise bionics, the symbiosis theory gives us a complete new view on this problem. The relationships between enterprises in supply chain are actually different kinds of symbiosis models. So we can take use of symbiosis theory to analysis the role of information sharing in supply chain, and according to different types of symbiosis models which have different information sharing characteristics. We can get a clear theoretic explanation on why we share information, and give a guideline that sharing "what" to" who" is most properly. Further, this research could set an example for us to research other problem with biology theory. 


\section{The Symbiosis Theory}

In the economic society, the different enterprise's relationship is similar to the one between different kinds of species in the nature. Chinese scholar Chunqing Yuan thinks [1] "Symbiosis is the relationship which come into being according to some kind of symbiosis pattern between the symbiosis units under certain symbiosis environment" and proposed a better complete symbiosis theory system.

\subsection{Basic concept of symbiosis}

\section{1 .1 Symbiosis system}

The symbiosis system is the set of symbiosis relations which symbiosis units formed under certain symbiosis model. The state of symbiosis system is decided by symbiosis organizing mode and symbiosis behavior mode.

In the symbiosis theory, there are four symbiosis modes:

They are as follows:

a. single-point symbiosis mode:

They formed symbiosis relationships, when $\forall t=t_{0}, \psi=\psi_{0}$, if $\delta_{i j}^{m}>0$

b. Not continuous symbiosis mode some not continuous combination of $(T, \psi)$, This is $T=t_{1}, t_{2} \ldots \ldots t_{p}$; $\psi=\psi_{1}, \psi_{2} \ldots \ldots \psi_{p}$. And during all the combination, $\delta_{i j}^{m}>0$ is formed.

c. continuous symbiosis mode

When $T \in\left[t_{0}, t_{p}\right], t_{p} \neq 0 ; \psi \in\left[\psi_{0}, \psi_{p}\right] \psi_{p} \neq 0$, to every symbiosis unit $\delta_{i j}^{m}>0$ is existed.

d. Integrative symbiosis mode

A complete new symbiosis model, the symbiosis units formed a particular interface, the symbiosis lost some of their unattached ability, and the symbiosis body also gains something that they never do.

\subsubsection{Symbiosis Energy Function}

To evaluate the effect of symbiosis units' mutual influence, the symbiosis theory introduced symbiosis energy function. The definition [1] of symbiosis energy function: In a symbiosis system with $\mathbf{n}$ dimensions, if the symbiosis energy of unit $i$ is marked with $E_{i}$ under no symbiosis, the additional symbiosis energy got from symbiosis system is $\Delta \mathrm{E}$, the symbiosis energy function of this system is:

$$
\mathbf{E}=\sum_{\mathbf{i}=1}^{\mathbf{n}} \mathbf{E}_{\mathbf{i}}+\mathbf{\Delta E}
$$

$\mathrm{E}_{\mathrm{i}}$ And $\Delta \mathrm{E}$ are decided by $Z_{\mathrm{i}}, \mathrm{M}_{\mathrm{i}}, \rho_{\mathrm{j}}, \theta_{\mathrm{ij}}, \eta_{\mathrm{j}}, \lambda$, and $\delta_{\mathrm{ij}} . Z_{\mathrm{i}}$ is the main nature parameter of symbiosis unit $i . M_{i}$ is the symbiosis mode of unit $i, \theta_{i j}$ is 
symbiosis coefficient, $\rho_{\mathrm{j}}$ is symbiosis density,$\eta_{\mathrm{j}}$ is symbiosis dimension, $\delta_{\mathrm{ij}}$ is symbiosis degree, $\lambda$ is the eigenvalue of interface.

$$
\Delta \mathrm{E}=\mathrm{E}_{\mathrm{s}}=\mathrm{f}\left(\mathrm{Z}_{\mathrm{a}}, Z_{\mathrm{b}}, \theta_{\mathrm{ab}}, \lambda, \rho_{\mathrm{sa}}, \rho_{\mathrm{sb}}, \eta_{\mathrm{sa}}, \eta_{\mathrm{sb}}\right)
$$

\section{The application of symbiosis theory to information sharing of supply chain}

We can apply the symbiosis theory to analyzing the information sharing between enterprises in supply chain.

\subsection{The Symbiosis Behavior Analysis of a Simple Two-Dimensional Enterprises Ecology Model in Supply Chain}

Hall divides enterprise's relations into three types: "two-dimensional pattern ", " the radiation pattern " and "the network pattern ". In fact, "the network "and "the radiation pattern" is more common, but between the interior enterprise's relations is the superimposition of different "two-dimensional pattern ".

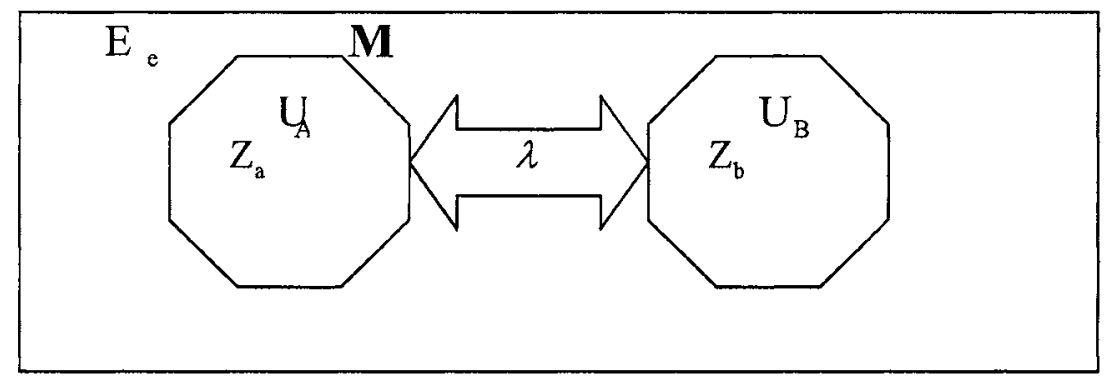

Chart 1. Two-dimensional enterprise symbiosis model

So, the enterprise's relations in supply chain can be simplified to "two-dimensional pattern". Establishing a "two-dimensional pattern" information sharing model under the hypothesis that this cooperation with other enterprise and other affect factors are regarded as enterprises' symbiosis environment.

$E_{e}$ is symbiosis environment; $U_{A}, U_{B}$ stand for the symbiosis units $A$ and $B$ which are enterprises in supply chain. The symbiosis relation is $S=\left(U_{A}, U_{B}, M\right.$, $\mathrm{E}_{\mathrm{e}}$ ).

Based on symbiosis theory, the energy function of this model is:

Total energy: $\quad E=E_{a}+E_{b}+\Delta E$

Increment of energy:

$$
\Delta \mathrm{E}=\mathrm{E}_{\mathrm{s}}=\mathrm{f}\left(\mathrm{Z}_{\mathrm{a}}, \mathrm{Z}_{\mathrm{b}}, \theta_{\mathrm{ab}}, \lambda, \rho_{\mathrm{sa}}, \rho_{\mathrm{sb}}, \eta_{\mathrm{sa}}, \eta_{\mathrm{sb}}\right)
$$

Further, the model only two-dimensional, so ignores the symbiosis dimension and the symbiosis density, then the type 3-2 may be simplified to:

$$
\Delta \mathrm{E}=\mathrm{E}_{\mathrm{s}}=\mathrm{f}\left(\mathrm{Z}_{\mathrm{a}}, \mathrm{Z}_{\mathrm{b}}, \theta_{\mathrm{ab}}, \lambda,\right)
$$


$Z_{a}, Z_{b}$ are the main nature parameters of enterprises symbiosis units. Between the enterprises in supply chain, inevitably exists relations, this is $Z_{\mathrm{ai}}=\varphi\left(Z_{\mathrm{bj}}\right)$.the relations are the source of foundation of increment of symbiosis energy. The associate coefficient is the parameter which measures the degree of cooperation. It increases with the improvement of symbiosis organization mode and intensity of coevolving. $\lambda$ is the eigenvalue of interface, if $\lambda$ is smaller, it means that the cooperation between enterprises is closer, the interface is broader, the contact medium is better; then the resistance of exchanges is smaller, symbiosis organization is more advantageous to the new energy production. Therefore, improving the information sharing between enterprises contributes to getting more competition advantages from the cooperation of supply chain.

Symbiosis theory is applied to analyzing the role of information sharing in the two-dimensional enterprise symbiosis model. The result is shown in following chart.

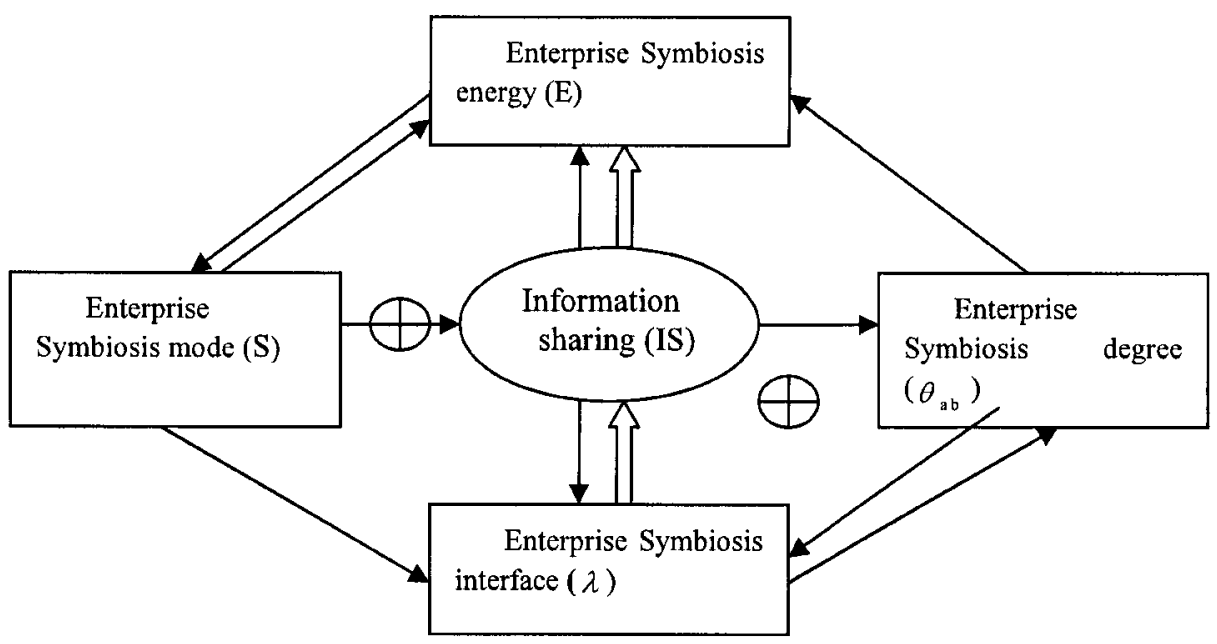

Fig.1 Information sharing function

Figure 1 clearly demonstrates the necessity of carrying on information sharing between enterprises in supply chain. Effective information sharing may bring two positive feedbacks to enhance the production of additional symbiosis energy.

(1)S-- $\lambda$--IS--E--S.

According to the characteristics of cooperation, the enterprises choose their symbiosis mode, then establish symbiosis interface to exchange material and share information. The information sharing is the only way for symbiosis interface to control the symbiosis, divide the work and cooperate with other units. This is the essence of enterprise symbiosis. By the harmony function of information sharing, the symbiosis produces more and more symbiosis energy. This is also the process of 
supply chain getting its competition advantage. When the symbiosis energy approaches the critical point, the symbiosis state will change, therefore, more deeply cooperation relation is formed. The new symbiosis mode will demand further information sharing which will bring more quick energy accumulation.

(2)IS-- $\theta_{\mathrm{ab}}--\lambda-\mathrm{IS}$

Highly efficiency information sharing will promote the mutual influence between symbiosis enterprises and improve the parameter $\theta_{\mathrm{ab}}$. If the enterprise symbiosis degree is improved, the symbiosis body will require more information sharing. This is a positive feedback cycle.

In essence, Symbiosis is a process of self-organizing. The elevation of whole enterprise ecology system is the fundamental source of enterprise development.

The existence of symbiosis interface characteristic value $\lambda$, also proves that sharing information should be paid.

Therefore, the information sharing is very necessary. But the best form of information sharing is not the most extensive information sharing, but the rational, temperate information sharing.

\subsection{Strategic Analysis of the Information Sharing in Supply Chain Based on Symbiosis Theory}

According to the symbiosis theory, different symbiosis modes need different ranks of information sharing. Firstly, enterprises could recognize the symbiosis modes between the enterprises and his partners by the characteristics of different symbiosis modes. Secondly, we can summarize the information that maybe shared in supply chain, and divide them into four ranks depending on the risk that brings to the company if the information is shared. Lastly, the enterprise will allocate different information sharing ranks to his partners by their symbiosis mode. By this way, the enterprise will meet the need of different symbiosis modes with lower information sharing risk cost

According to the analysis above, the conclusion is as follows:

\begin{tabular}{|c|c|c|c|c|}
\hline & $\begin{array}{l}\text { Single-point } \\
\text { symbiosis } \\
\text { mode }\end{array}$ & $\begin{array}{l}\text { Non- } \\
\text { continuous } \\
\text { symbiosis } \\
\text { mode }\end{array}$ & $\begin{array}{l}\text { Continuous } \\
\text { symbiosis } \\
\text { mode }\end{array}$ & $\begin{array}{l}\text { Integrative } \\
\text { symbiosis } \\
\text { mode }\end{array}$ \\
\hline $\begin{array}{c}\text { Characteristics } \\
\text { of } \\
\text { synergy evolution }\end{array}$ & Not obvious & $\begin{array}{l}\text { Relative } \\
\text { obvious }\end{array}$ & Obvious & Very obvious \\
\hline $\begin{array}{c}\text { Requirement of } \\
\text { information } \\
\text { sharing }\end{array}$ & Unilaterally & Minority aspect & Majority aspect & Entire \\
\hline $\begin{array}{c}\text { Rank of } \\
\text { information } \\
\text { sharing }\end{array}$ & Work rank & Management \\
rank & Strategy rank & Core rank \\
\hline
\end{tabular}

Table 1. Symbiosis mode and its information sharing rank 


\section{Conclusions}

The article research the necessity of information sharing from the view of symbiosis energy, establish a two-dimensional enterprise symbiosis mode, draws the conclusions that:

1. To the different symbiosis mode in supply chain, the symbiosis system needs reasonable necessity information sharing, to satisfy the request of evolution together.

2. The existence of information risk cost.

3. For different ranks if symbiosis mode, the article authorize different ranks of in formation sharing.

The research is too superficial. First, the real relation between two enterprises in supply chain may deeply affected by other cooperation which is among other enterprises. Secondly, to different type of enterprise, the significance of same type information is various. But the research of apply symbiosis theory to information sharing will provide a new way to deal with this problem. Further, the symbiosis theory could be used to many other aspects for management research.

\section{Acknowledgements}

The authors would like to thank Professor Lida $\mathrm{Xu}$ for his insightful and helpful comments. We are grateful for the funding from Bureau of Science and Technology in Shaanxi Province (Grant No.2004KR59), and "985" two term "07" base in Xian Jiaotong University.

\section{References}

1. Y. Chunqing, The Symbiosis Theory (Economic Science Press, Beijing, 1998).

2. J. Sapp, Concepts of Symbiogenesis (Yale University Press, 1992).

3. L.Margulis and R. Fester, Symbiosis as a source of Evolutionary Innovation (MIT Press, 1991).

4. A. E. Douglas, Symbiotic Interactions (Oxford University Press, 1994).

5. M.T. Hannan and J. Freeman, Organizational Ecology (Oxford University Press, 1989).

6. A. Alchian, A Uncertainty Evolution and Economic Theory, Journal of Political Economy 58211-222 (1950).

7. C. Andrew and A. Marcus, What's Wrong with Strategy, Harvard Business Review, 75, 42 50 (1997).

8. J.A. Parnell, D.L. Lester, and M.L. Menefee, Strategy as a Response to Organizational Uncertainty: An Alternative Perspective on the Strategy-Performance Relationship, Management Decision 38, 520-530 (2000).

9. G.A. Hedlund, Model of Knowledge Management and the N-form Corporation, Strategic Management Journal 15, 73-90 (1994). 
10. E.T. Penrose, The Theory of the Growth of the Firm (Oxford University Press, London, 1995).

11. C.E. Helfat and R.S. Paubitschek., Product Sequencing: Co-Evolution of Knowledge, Capabilities and Products, Strategic Management Journal 21, 961 -979 (2000).

12. K.M. Eisenhardt, and C.B. Schoonhoven, Resource-Based View Of Strategic Alliance Formation Strategic and Social Effects In Entrepreneurial Firms, Organization Science 7,136162 (1996).

13. B. Lovas and S. Ghoshal, Strategic as Guided Evolution, Strategic Management Journal 21, 875-896 (2000).

14. E.L. Hansen, Entrepreneurial Networks and New Organization Growth, Entrepreneurship Theory and Practice 19, 7-19 (1995).

15. S. Ma, Management of Supply Chain (China Machine Press, Beijing, 2002). 